\title{
Research of Strategic Transformation of SMEs in China from International Perspective
}

\author{
Qian Cao \\ School of Management and Economics, University of Electronic Science and Technology of China, \\ Chengdu 610054, China \\ 963294732@qq.com
}

Keywords: China's civil aviation industry, Fuel consumption, BP neural network, $\operatorname{GM}(1,1)$.

\begin{abstract}
With market-oriented opening in the China's civil aviation industry and the rapid development of China's economy, China's civil aviation transportation fuel consumption has grown significantly in nearly past three decades. Therefore, it's a very important strategic significance of the prediction of China's civil aviation transportation fuel consumption. In this paper, by using gray system and neural network approach, combined with China's civil aviation industry 1980-2010 total traffic volume of the data, we establish gray system GM $(1,1)$ model and BP neural network model for civil aviation transport volume. Training and simulation of the back propagation neutral network model and the gray system GM(1,1) are used by MATLAB. BP neural network modeling takes into account three factors: the number of aircraft aviation industry, flight hours and total turnover. The fitting precision of the gray system $\operatorname{GM}(1,1)$ model is $64.2 \%$ while the fitting precision of the back propagation neutral network model is $90.16 \%$. Thus, the back propagation neutral network model is better for estimating civil aviation fuel consumption.
\end{abstract}

\section{Introduction}

China's civil aviation industry separates from the military jurisdiction and gradually returns to the market since 1980, has more than 30 years. In three decades of market-oriented process, China's civil aviation industry has experienced rapid development. We can say that China's rapid economic development has effectively led the aviation industry. In this process, China's civil aviation industry has grown, the number and size of civil aviation enterprises expanding. There are six state-owned airlines in China's aviation industry, and it was 43 in the end of 2010. The categories include state-owned airlines, private airlines and joint venture airlines. At the same time, China's civil aviation industry fuel consumption is also increasing. Therefore, the aviation fuel consumption forecast is even more important.

Fuel consumption in itself is a non-linear, complex and open system, is the result of interaction of many factors. Some factors such as political and economic factors, and some unexpected events (such as natural disasters, disease and terrorist attacks, etc.) and other factors are included. Because of the unpredictable nature of these factors, or the absence of such information, while the predictive modeling works to bring a certain degree of difficulty, which affects the prediction accuracy of the results.

Grey prediction method is proposed by Professor Deng Julong gray system theory prediction method in 1980s. For the information is incomplete or imperfect situation has good applicability, one single sequence of first-order GM $(1,1)$ dynamic model has fewer samples, modeling and widely used in the country. BP (back propagation) neural network is Rumelhart and McCelland 1986 by a team of scientists led by proposed is a method of error back propagation algorithm to train multi-layer feedforward neural networks, is currently the most widely used one neural network model. BP neural network can learn and store a large number of input - output mode mappings without prior description of this mapping reveals the mathematical equations. BP neural network with non-linear, parallel distributed processing, self-learning, self-organizing, adaptive, etc. can accurately simulate the real demand for aviation fuel.

In this paper, with China's civil aviation 1980-2010 fuel consumption data for 31 years, gray 
system and neural network approach are used to build China's civil aviation fuel consumption of Grey System GM $(1,1)$ model and BP neural network model. Studying fuel consumption prediction method can predict the future of aviation fuel consumption for business decisions and provide reference for government policy makers to realize the sustainable development of civil aviation.

\section{Data}

According to the China Air Transport statistics from published annually by the Civil Aviation Authority, we get data from 1980 to 2010 aviation fuel consumption from the "Statistical data on Civil Aviation of China 2010."

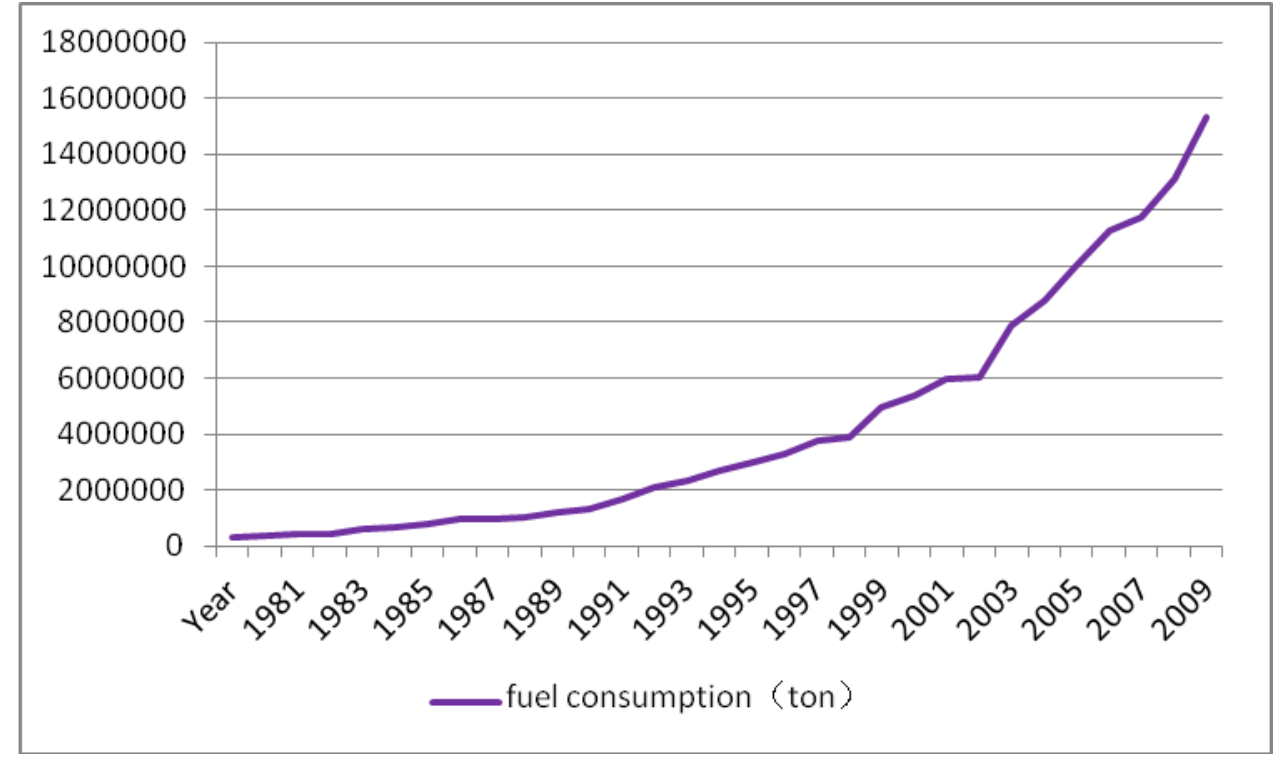

Fig. 1 1980-2010 China's civil aviation transportation fuel consumption

\section{Grey System GM $(1,1)$ model}

The fuel consumption of China's civil aviation transportation from 1980 to 2010 is defined as GM $(1,1)$ model of the original series $x^{(0)}$. Forecast 2011-2020 total turnover. Modeling process includes generating a cumulative sequence, using the mean cumulative number of solved column parameters and the least square method for solving gray parameters into the differential equations for modeling and prediction of the original sequence.

$$
x^{(0)}=\left(x^{(0)}(1), x^{(0)}(2), \cdots, x^{(0)}(n)\right) .
$$

where $n$ represents the number of samples of the original series, Here $n=31$.

1 number of times as cumulative is:

$$
x^{(1)}=\left(x^{(1)}(1), x^{(1)}(2), \cdots, x^{(1)}(n)\right) .
$$

And $x^{(1)}(1)=x^{(0)}(1), x^{(1)}(k)=x^{(1)}(k-1)+x^{(0)}(k)$.

Mean number listed is:

$$
z^{(1)}=\left(z^{(1)}(1), z^{(1)}(2), \cdots, z^{(1)}(n-1)\right) .
$$

And $z^{(1)}(k)=0.5 x^{(0)}(k)+0.5 x^{(0)}(k+1)$.

Whitening system differential equations is:

$$
\frac{d x^{(1)}}{d t}+a x^{(1)}=d
$$


Its time response function that is the solution of the differential equation is:

$$
\hat{x}^{(1)}(k+1)=\left(x^{(0)}(1)-u / a\right) e^{-a k}+u / a \text {. }
$$

The solution to restore the original sequence simulation solution is:

$$
\hat{x}^{(0)}(k+1)=\left(1-e^{a}\right)\left(x^{(0)}(1)-u / a\right) e^{-a k} .
$$

The gray parameters $(a, u)$ which are obtained by least squares method, the using equation is:

$\left[\begin{array}{l}a \\ u\end{array}\right]=\left(B^{T} B\right)^{-1} B^{T} Y_{n}$.

And $B=\left[\begin{array}{rc}-z^{(1)}(1) & 1 \\ -z^{(1)}(2) & 1 \\ \vdots & \vdots \\ -z^{(1)}(n-1) & 1\end{array}\right], \quad Y_{N}=\left[x^{(0)}(2), x^{(0)}(3), \cdots, x^{(0)}(n)\right)^{T}$.

Meanwhile, calculation model accuracy which is calculated as:

$$
s=1-\frac{1}{N} \sum_{i=1}^{N} \frac{\left|t_{i}-t_{i}^{\prime}\right|}{t_{i}} \times 100 \% .
$$

Wherein $s$ represents the model accuracy, the number of samples $N, t_{i}$ is a sample value (actual value) of $t_{i}^{\prime}$ analog values.

\section{Bp Neural Network Modeling}

BP neural network is a multilayer feed forward neural network, and the topology consists of three layers: the input layer, hidden layer and output layer.

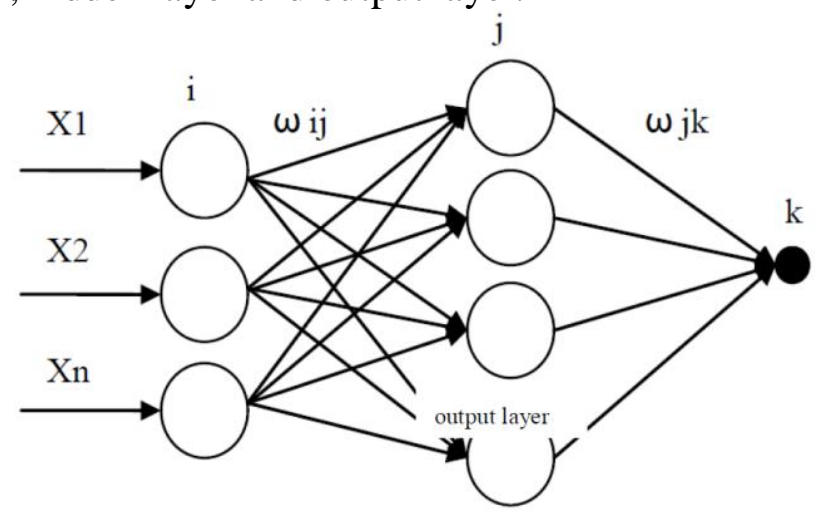

input layer hidden layer output layer

Fig. 2 Multi-layer structure of a neural network

We make the fuel consumption as the output vectors, and the number of aircraft, flight hours, with a total turnover and airline mileage and other four factors are the impact on fuel consumption input vector. While the dimension difference of input and output vectors is standardized, so that they have zero mean and a standard deviation of unity.

Here, we choose a hidden layer of BP neural network. Nodes in the input layer dimension of the input vectors dimension is 4 , so the input layer nodes identified as 4 . Output layer nodes have determined the dimension of input vectors, where the output nodes is 1 . Hidden layer node selection 
is currently no theoretical guidance, too much will increase the network node network training time and reduce the generalization ability of the network. But too little network nodes cannot effectively learn the training samples, modeling insufficient. Hidden layer nodes can refer to the following formula:

$$
h=(m+n)^{\frac{1}{2}}+a .
$$

Number of nodes in the hidden layer and the input layer nodes for the output layer nodes are an integer which is between 1 and 10. According to equation (9), hidden layer nodes are initially identified through repeated training, and finally determine the hidden layer nodes, which is 8 . Thus, form a 4-8-1 BP neural network.

The sample data from 1980 to 2000 is used as the training sample set, and the data 2001-2006 2010 sample data is used as the test sample set. MATLAB is used for data programming and analysis. While, the test sample data tests the model.

\section{Results}

Tab. 1 Grey System GM $(1,1)$ model simulation results

\begin{tabular}{|c|c|c|c|c|c|c|c|}
\hline Year & $\begin{array}{c}\text { Fuel } \\
\text { consumption } \\
\left(10^{3} \text { tons }\right)\end{array}$ & $\begin{array}{c}\text { value of } \\
\text { simulation }\end{array}$ & $\begin{array}{c}\text { Relative } \\
\text { error }\end{array}$ & Year & $\begin{array}{c}\text { Fuel } \\
\text { consumption } \\
\left(10^{3} \text { tons }\right)\end{array}$ & $\begin{array}{c}\text { value of } \\
\text { simulation }\end{array}$ & $\begin{array}{c}\text { Relative } \\
\text { error }\end{array}$ \\
\hline 1980 & 340 & 340 & $0.07 \%$ & 1996 & 3014 & 2710 & $24.90 \%$ \\
\hline 1981 & 376 & 555 & $47.70 \%$ & 1997 & 3275 & 3097 & $29.52 \%$ \\
\hline 1982 & 413 & 625 & $51.36 \%$ & 1998 & 3776 & 3704 & $26.62 \%$ \\
\hline 1983 & 445 & 705 & $58.48 \%$ & 1999 & 3874 & 4043 & $39.12 \%$ \\
\hline 1984 & 602 & 895 & $48.58 \%$ & 2000 & 4941 & 4844 & $22.92 \%$ \\
\hline 1985 & 660 & 1009 & $52.91 \%$ & 2001 & 5356 & 5750 & $27.85 \%$ \\
\hline 1986 & 782 & 1137 & $45.46 \%$ & 2002 & 6001 & 6076 & $28.60 \%$ \\
\hline 1987 & 970 & 1282 & $32.12 \%$ & 2003 & 6049 & 6040 & $43.80 \%$ \\
\hline 1988 & 988 & 1445 & $46.29 \%$ & 2004 & 7888 & 7308 & $24.29 \%$ \\
\hline 1989 & 1009 & 1628 & $61.35 \%$ & 2005 & 8781 & 9131 & $25.85 \%$ \\
\hline 1990 & 1186 & 1835 & $54.67 \%$ & 2006 & 10005 & 10582 & $24.49 \%$ \\
\hline 1991 & 1324 & 2069 & $56.24 \%$ & 2007 & 11299 & 11142 & $24.25 \%$ \\
\hline 1992 & 1697 & 2332 & $37.40 \%$ & 2008 & 11745 & 11302 & $34.72 \%$ \\
\hline 1993 & 2115 & 2628 & $24.28 \%$ & 2009 & 13142 & 13203 & $35.72 \%$ \\
\hline 1994 & 2351 & 2962 & $25.96 \%$ & 2010 & 15314 & 15313 & $31.28 \%$ \\
\hline 1995 & 2714 & 3339 & $23.01 \%$ & - & - & - & - \\
\hline
\end{tabular}

Tab. 2 BP neural network model simulation results

\begin{tabular}{|c|c|c|c|c|c|c|c|}
\hline Year & $\begin{array}{c}\text { Fuel consumption } \\
\left(10^{3} \text { tons }\right)\end{array}$ & $\begin{array}{c}\text { value of } \\
\text { simulation }\end{array}$ & $\begin{array}{c}\text { Relative } \\
\text { error }\end{array}$ & Year & $\begin{array}{c}\text { Fuel consumption } \\
\left(10^{3} \text { tons }\right)\end{array}$ & $\begin{array}{c}\text { value of } \\
\text { simulation }\end{array}$ & $\begin{array}{c}\text { Relative } \\
\text { error }\end{array}$ \\
\hline 1980 & 340 & 467 & $37.45 \%$ & 1996 & 3014 & 2710 & $10.07 \%$ \\
\hline 1981 & 376 & 501 & $33.33 \%$ & 1997 & 3275 & 3097 & $5.44 \%$ \\
\hline 1982 & 413 & 463 & $12.13 \%$ & 1998 & 3776 & 3704 & $1.90 \%$ \\
\hline 1983 & 445 & 281 & $36.83 \%$ & 1999 & 3874 & 4043 & $4.37 \%$ \\
\hline 1984 & 602 & 341 & $43.39 \%$ & 2000 & 4941 & 4844 & $1.97 \%$ \\
\hline 1985 & 660 & 544 & $17.56 \%$ & 2001 & 5356 & 5750 & $7.36 \%$ \\
\hline 1986 & 782 & 759 & $2.90 \%$ & 2002 & 6001 & 6076 & $1.25 \%$ \\
\hline 1987 & 970 & 868 & $10.55 \%$ & 2003 & 6049 & 6040 & $0.15 \%$ \\
\hline 1988 & 988 & 954 & $3.42 \%$ & 2004 & 7888 & 7308 & $7.35 \%$ \\
\hline 1989 & 1009 & 1021 & $1.19 \%$ & 2005 & 8781 & 9131 & $3.99 \%$ \\
\hline 1990 & 1186 & 1181 & $0.46 \%$ & 2006 & 10005 & 10582 & $5.76 \%$ \\
\hline 1991 & 1324 & 1417 & $7.01 \%$ & 2007 & 11299 & 11142 & $1.39 \%$ \\
\hline 1992 & 1697 & 2062 & $21.49 \%$ & 2008 & 11745 & 11302 & $3.78 \%$ \\
\hline 1993 & 2115 & 2346 & $10.94 \%$ & 2009 & 13142 & 13203 & $0.47 \%$ \\
\hline 1994 & 2351 & 2452 & $4.28 \%$ & 2010 & 15314 & 15313 & $0.01 \%$ \\
\hline 1995 & 2714 & 2527 & $6.90 \%$ & - & - & - & - \\
\hline
\end{tabular}




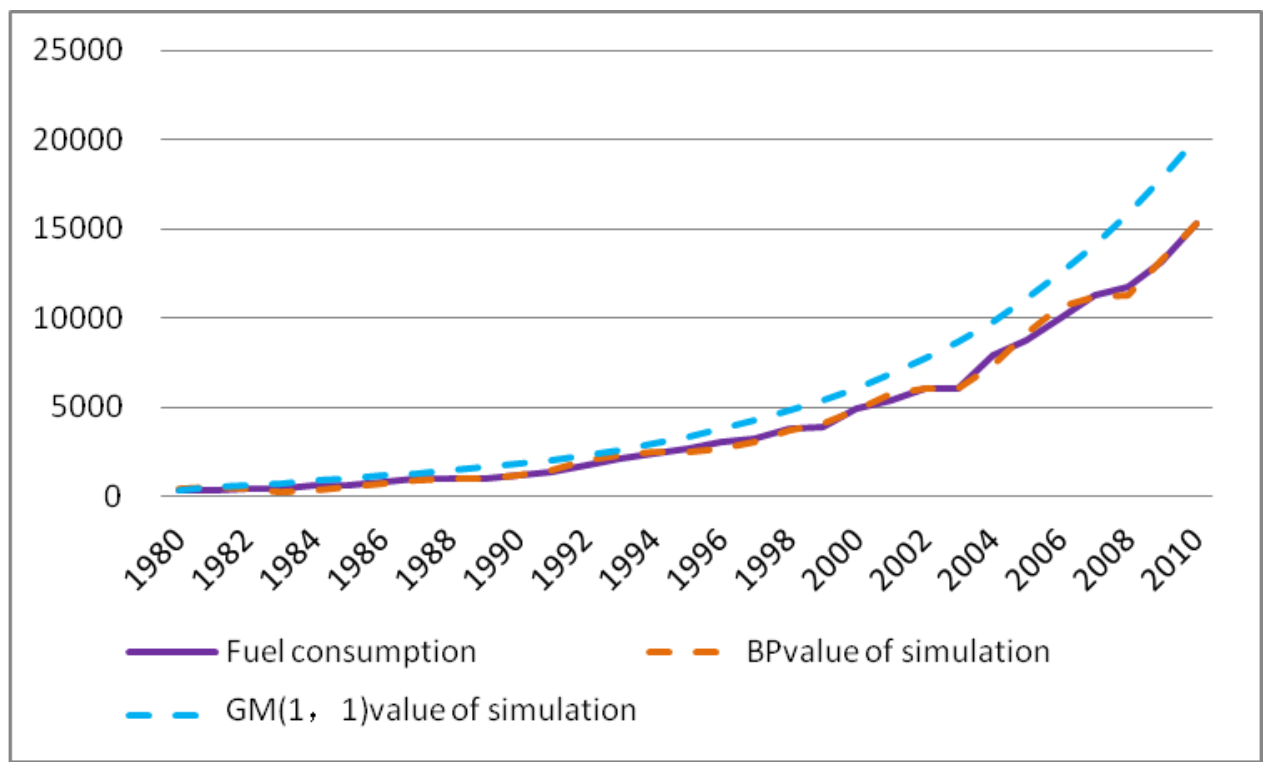

Fig. 3 True values and simulated comparison

\section{Summary}

In this paper, gray system GM $(1,1)$ model and BP neural network model from 1980-2010 China's civil aviation industry aviation fuel consumption simulation are studied. The results showed that: BP neural network model has a strong self-organizing, self-learning, adaptive capacity, and gray system GM $(1,1)$ model is better suited for the civil aviation industry aviation fuel consumption prediction. BP neural network model can be used in the China's future civil aviation industry development trend of aviation fuel consumption forecast for government policy makers to provide a reference.

\section{References}

[1] The Civil Aviation Administration of China Development and Planning Department. Statistical data on Civil Aviation of China. [M].Beijing: China Civil Aviation press, 2012. (in Chinese)

[2] LIU Sifeng, DANG Yaoguo, FANG Zhigeng, XIE Naiming. Grey System Theory and Its Applications(5nd Edition) [M].Beijing:Science Press,2010. (in Chinese)

[3] DENG Julong. A Primary Methods of Grey System Theory(2nd Edition)[M].Wuhan:Huazhong University of Science and Technology Press,2005. (in Chinese)

[4] DENG Julong. Introduction to grey system theory[J]. The Journal of Grey System, 1989(1): $1-24$.

[5] HE Changhong, SHEN Shifei, HUANG Quanyi. Predication method for college and university enrollment scale[J]. The Journal of Tsinghua Univ(Sci \& Tech), 2012, Vol. 52, No.1.

[6] CAI Jibo, CHEN Haibo. Prediction Research on China's R\&D Input Intensity Based on GM (1, 1) Model[J].Science and Technology Management Research,2010, No.21.

[7] YANG Jun, LIU Bin, SHANG Manlong. Forecast of Soybean Import in China[J]. Systems Engineering-Theory \& Practice,2006, No.6. 